UDC 316.3

LBC 60.52

\title{
IDENTITY AS A SOCIOCULTURAL PHENOMENON ${ }^{1}$
}

\author{
Ilya V. Demichev \\ Institute of Strategic Research of Republic Bashkortostan, \\ Ufa, Russian Federation \\ Gulfina D. Sultanova \\ Institute of Strategic Research of Republic Bashkortostan, \\ Ufa, Russian Federation
}

\begin{abstract}
This article is devoted to the analysis of identity as a sociocultural phenomenon related to the nature and functioning of socio-cultural communities and their institutional and discursive organization. Based on consideration of the extensive amount of scientific literature notion of identity is interpreted as "self - and mutual representation of a person or group on the basis of which their correlation with the entity of a higher order takes place". In the structure of identity there are the following elements: retainer, fixed image; the complex of social, cultural and material markers of attributes; a set of behaviors and communication; forms of solidarity. Reproduction of identity is caused by the operation of the special institutional and discursive structures that are rigidly tied to the specific organization of socio-cultural communities simultaneously being common to its structure and current processes.

Based on this, the general logical model of functioning of socio-cultural identities complex of community is considered, where there are the following evaluation criteria of estimating its efficiency of internal and external character. This is, firstly, the degree of reflexivity of the content of the identity which determines the meaningfulness and significance of the plants of the identity of the representatives of the respective community; the prevalence of identity among members of the community; the degree of connectivity of elements and options of this identity between them. Secondly, the degree of security of the reproduction of identity in institutional and discursive terms; the degree of complementarity of the identity with the other elements of the system - assessed the level of mutual compliance, cash identities in a sociocultural system; the degree of conflict - on the contrary, the level of mutual inconsistency and rejection between this identity and other elements of the system. It then discusses the relationship and interaction of selected criteria, which form the logic structure of the entire system of identities of the community. External and internal criteria are interlinked and mutually affect each other: for example, weak reflexivity of identity means as a lack of structural security as the lack of cohesion of its units. However, this effect is not clear - weak reflexivity of identity can as enhance its complementarity with other identities in the system because it has less rigid settings as to increase its conflict since fewer settigs can have a greater emotional intensity among carriers of identity.

Key words: identity, definition of identity, collective identities, institutional and discursive structures, criteria of identity, identity dynamics.
\end{abstract}

\section{ИДЕНТИЧНОСТЬ КАК СОЦИОКУЛЬТУРНЫЙ ФЕНОМЕН ${ }^{1}$}

\author{
Илья Валерьевич Демичев
}

Институт стратегических исследований Республики Башкортостан, г. Уфа, Российская Федерация

Гульфина Дамировна Султанова

Институт стратегических исследований Республики Башкортостан, г. Уфа, Российская Федерация 
Аннотация. Данная статья посвящена анализу идентичности как социокультурного феномена, относящегося к сущности и функционированию социокультурных общностей и их институциально-дискурсивной организации. На основании рассмотрения обширного объема научной литературы выводится определение идентичности, которая трактуется как «само- и взаиморепрезентация личности или группы, на основании которой происходит их соотнесение с общностью более высокого порядка». В структуре идентичности выделяются следующие элементы: фиксирующее название; фиксируемый образ; комплекс социальных, культурных и материальных маркеров, атрибутов; комплекс стереотипов поведения и общения; формы солидарности. Воспроизводство идентичности обусловливается функционированием специальных институционально-дискурсивных структур, которые жестко привязаны к специфике организации социокультурной общности, а также общей ее структуре и текущим процессам.

На основании этого рассматривается общая логическая модель функционирования системы идентичностей сложной социокультурной общности, где выделяются следующие критерии оценки ее дееспособности внутреннего и внешнего характера. Это, во-первых, степень рефлексивности содержания идентичности, которая определяет осмысленность и значимость установок идентичности для представителей соответствующего сообщества; степень распространенности идентичности среди представителей сообщества; степень связности элементов и вариантов данной идентичности между собой. Во-вторых, степень обеспеченности воспроизводства идентичности в институциональном и дискурсивном планах; степень комплементарности данной идентичности другим элементам системы - оценивается уровень взаимного соответствия наличных идентичностей в социокультурной системе; степень конфликтности - наоборот, уровень взаимного несоответствия и отторжения между данной идентичностью и другими элементами системы. Далее рассматриваются взаимосвязь и взаимовлияние выделенных критериев, образующих логику структуры всей системы идентичностей данной общности. Внешние и внутренние критерии связаны между собой и взаимно влияют друг на друга: например, слабая рефлексивность идентичности означает как недостаточную структурную обеспеченность, так и недостаточную связность ее установок. Однако это влияние не однозначно - слабая рефлексивность идентичности может как повышать ее комплементарность другим идентичностям системы, поскольку в ней меньше жестких установок, так и повышать ее конфликтность, поскольку меньшее количество установок может иметь большую эмоциональную насыщенность среди носителей идентичности.

Ключевые слова: идентичность, определение идентичности, коллективная идентичность, институционально-дискурсивные структуры, критерии идентичности, динамика идентичности.

Идентичность складывается в рамках социального взаимодействия и имеет групповую и индивидуальную стороны [3, 7-11]. В индивидуальном плане идентичность представляет собой комплекс представлений индивида о самом себе и об окружающих его людях, группах и общностях, воспринятых и отрефлексированных в ходе такого взаимодействия. В коллективном плане идентичность выступает комплексом атрибутивных установок поведения, общения и мышления, характеризующих членов коллектива, группы или общности. При этом индивидуальные идентичности относительно гибки в силу вариативности индивидуальных ситуаций и множественности социального окружения, разной степени вовлеченности в различные группы; коллективные же идентичности, наоборот, в значительной степени жестки, поскольку представляют собой предзаданные принципы взаимодействия [12]. В то же время отношения между индивидуальными и коллективными идентичностями носят диалектический, взаимозави- симый характер, поскольку коллективные определяют общие установки индивидуального поведения, общения и мышления, но реальное совокупное поведение, общение и мышление трансформируют коллективные установки в ходе своей реализации [3].

Совокупность индивидуальных идентичностей образует полную идентичность личности и лежит в основе ее социальной деятельности, поэтому важным выступает вопрос взаимной комплементарности общностей, в которые индивиды входят: в случае их несовместимости личность теряет свою целостность и фрустрируется. Схожий процесс можно выделить и в общности при условии чрезмерной специализации и отличиях составляющих ее частей - вариативность общей идентичности и субидентичностей возможна в каком-то пределе, выход за который будет определять появление новых идентичностей и определенную оппозиционность между ними. Сходство полных идентичностей или их значимых элементов формирует большие соци- 
альные сообщества - страты, классы и т. п., которые, хотя и не образуют относительно связные и функциональные группы, складываются в группы с похожим характерным социальным поведением, общением и мышлением [4].

Исходя из этого нельзя не отметить доминирующее значение коллективных идентичностей: они предписывают установки индивидам, а последние, в силу своей деятельности, адаптируются тем или иным образом, в том числе и посредством внесения изменений, к первым [3].

Коллективные идентичности выступают комплексом принципов поведения, общения и мышления, которые не просто характерны для данных групп и общностей - они выступают совокупностью социальных ролей и статусов, функциональных для данного коллектива, по которым распределяются составляющие его индивиды. Именно этим обусловливается как институциональная организации общности, так и составляющие ее сообщества, образуемые в рамках разделения труда или функций [8].

В то же время коллективные идентичности не сводятся к ролям и статусам, - последние выступают характерными особенностями, в соответствии с которыми происходит идентификация. Учитывая роль «воображения» при формировании идентичности, а также представленность общности в качестве некоторого рефлексивного образа, который воспринимается в ходе взаимодействия и общения, в процессе формирования идентичности на первый план выходит культура как комплекс образов, описывающих мир, общество и человека [2]. Именно здесь фиксируются и воспроизводятся «эталоны» социального поведения, представления о должном и недолжном, качества личности и т. П., которые ориентируют личность в ее деятельности и сопоставляются с социальной реальностью [5]. В этом смысле идентичность одновременно привязана к существующей культуре общности и ее институциональной организации - не столько к их конкретике, сколько к некоторым отрефлексированным и принципиальным формам, выступая, таким образом, «снятым видом» и «точкой фокуса» того и другого. Это позволяет выполнять основную функцию идентичности - сохранения и воспроизводства са- мотождественности данной общности и ее различения с другими.

Символическое пространство культуры охватывает и осваивает все условия и факты совокупного социального опыта, от ландшафта до исторических событий и нормативной личности. Из всей совокупности представлений, выраженных в актуальных и каноничных культурных нарративах, складывается некоторый обобщенный образ разной степени вариативности, который и лежит в основе содержания идентичности данной общности. Этот обобщенный образ можно также обозначить как «миф» данной культуры.

Вариативность «мифа» культуры и сложная, многофункциональная организация социальной системы создают сложный социокультурный контекст личностей и групп, что сказывается на множественности идентичностей. Среди них можно выделить локальные [1], профессиональные, стратовые [6]; если общность полиэтнична и многоконфессиональна, очевидно, нельзя не учитывать различия этнических и конфессиональных идентичностей. Кроме того, необходима еще и общая идентичность, «собирающая» эту множественность в систему [13], - действенность ее обеспечивает стабильность большой общности, а дисфункция обусловливает слабость общего социального порядка, что выражается не только в нарастании противоречий в социальной системе, но и повышении внутренней конфликтности. Кроме того, в целом множественность идентичностей усиливает их рефлексивность и повышает требования к взаимной комплементарности.

Таким образом, можно сформулировать следующее общее определение идентичности.

Идентичность - само- и взаиморепрезентация личности или группы, на основании которой происходит их соотнесение с общностью более высокого порядка. В ее структуре можно выделить следующие основные элементы:

- фиксирующее название; значимость этого элемента определяется тем, что именно он выступает основным маркером принадлежности и ключевым при взаимной репрезентации, в нем фокусируется идентичность как таковая;

- фиксируемый образ; этот элемент выступает основным содержанием идентичнос- 
ти, с которым происходит соотнесение личности или группы.

- комплекс социальных, культурных и материальных маркеров, атрибутов; этот элемент выступает внешней формой идентичности;

- комплекс стереотипов поведения и общения; на основании этого элемента происходит формирование социального и культурного взаимодействия между личностями и их группами, распределенными в зависимости от произведенной идентификации;

- формы солидарности; на основании этого элемента совокупности лиц с данной идентичностью образуют соответствующее сообщество.

Фиксация и воспроизводство идентичности обеспечивается в социальном и культурном планах соответствующими институционально-дискурсивными структурами, которые можно разделить на три типа: фоновые, то есть исполняющие рутинные функции воспроизводства структур большой социокультурной общности, в отношении которой происходит идентификация; побочные, в которых фиксируется и воспроизводится какой-либо специфический аспект социокультурной практики, выступающий также маркером идентичности; специализированные - структуры, непосредственно направленные на фиксацию и воспроизводство идентичности как таковой.

Первые определяют основное текущее и базовое содержание образов идентичности, вторые - выступают вариациями базовых образов в каком-либо отношении, территориальном, стратовом, профессиональном и т. д., определяя образы актуального субкультурного деления общности. Наконец, третьи непосредственно выступают специализированными структурами, в которых аккумулируется, рефлексируется, транслируется и актуализируется образ идентичности. Примером первых структур могут выступать институциональные и дискурсивные нормы типичных форм поведения в типичных сообществах - отношения дружбы и вражды, специфичные для общностей в зависимости от их культурных принципов, но неизбежно присутствующие у любых общностей, или специфика гендерных отличий в поведении, мышлении, внешнего образа и т. д. Примером вторых структур являются институцио- нальные и дискурсивные нормы, не обязательно выраженные в организациях: например, стилевые особенности поведения, общения и мышления - если «научный стиль» выступает частью научного сообщества и закреплен в академических организациях, то, скажем, стратовые стили поведения или субкультуры таких организаций не образуют, а соответствующие нормы просто воспроизводятся членами сообщества. Примером третьих структур выступают какие-либо организации, в которых производится соответствующая деятельность, - такие, как религиозные организации для конфессиональных сообществ (РПЦ МП, РИУ ЦДУМ или ДУМ РБ), которые прямо и непосредственно выполняют функции формирования, трансляции и защиты как основного конфессионального (как часть культурного) содержания, так и непосредственно самообраза верующих данной конфессии и их подгрупп; академические и университетские организации научного сообщества и т. п.

Эти структуры, в свою очередь, в социальном плане выступают основой институализации меж- и внутригруппового взаимодействия, где соответствие образу, реализация стереотипов и актуализация маркеров санкционируются положительно, а отход от них негативно. Таким образом, не только регламентируется индивидуальное поведение, но и складывается основа существования и функционирования коллективов и общностей.

Можно очертить основную логическую модель функционирования комплекса идентичностей сложной социокультурной системы. Здесь выделяются две стороны: во-первых, внутренняя для данной идентичности, а вовторых, внешняя, касающаяся соотношения и взаимодействия идентичностей друг с другом.

Внутренние критерии идентичности:

- степень рефлексивности содержания идентичности; оценивается объем и сложность идентичности и ее компонентов;

- степень распространенности идентичности; оценивается удельный вес идентичности, ее вариантов и компонентов в объеме социокультурной системы;

- степень связности; оценивается уровень комплементарности элементов и вариантов идентичности. 
Внешние критерии идентичности:

- степень обеспеченности; оценивается достаточность или недостаточность институционально-дискурсивных структур для фиксации, воспроизводства и трансформации идентичности в социокультурной системе;

- степень комплементарности; оценивается уровень взаимного соответствия наличных идентичностей в социокультурной системе;

- степень конфликтности; оценивается уровень взаимного противопоставления и напряженности идентичностей социокультурной системы.

Проблема выявления и внутренних, и внешних критериев также нетривиальна, поскольку одновременно требуется совмещать качественные характеристики, как правило значительно отличающиеся даже среди носителей идентичности, и количественные оценки по их распространенности в сообществе. Однако здесь будет довольно показательным тот факт, что сложность, спутанность своей и чужой идентичности уже будет означать ее малую рефлексивность, а идентичности с высокой степенью рефлексивности будут давать более содержательные ответы относительно всех остальных оцениваемых сторон. С другой стороны, по аналогии с институционально-дискурсивной корреляцией в значительной степени можно утверждать, что установки идентичности будут так или иначе концентрироваться в соответствующих группах и объединениях, и в каком-то отношении об их рефлексивности, связности, комплементарности или конфликтности можно судить по спектру этих групп и объединений, а о достаточности и распространенности - по уровню влияния этих групп и объединений, их узнаваемости и отношениям между собой. Хотя всегда надо иметь в виду, что общественные объединения любого характера не могут подменить собой представляемое сообщество, а транслируемые ими установки могут в различной степени разделяться членами этого сообщества.

Наглядным примером выступает современная конфессиональная идентичность и противоречия в принадлежности к конфессиональному сообществу: формальное самоотнесение к православным и мусульманам сопрягается с фактическим неисполнением религиозных предписаний и незнанием даже их базовых установок и текстов. С другой стороны, в конфессиональных сообществах всегда присутствуют подгруппы, которые, наоборот, будут достаточно строго придерживаться предписаний и разбираться в богословских и иных аспектах веры. В этом смысле первые будут отражать идентичность в слаборефлексивной форме, вторые - в высокорефлексивной. Соотношение количества первых и вторых, плотность контактов между ними и наличие переходных групп будут отражать не только социокультурную связность православного и мусульманского сообществ, но и совокупную рефлексивность и распространенность соответствующих идентичностей.

В связи с этим можно высказать ряд общих соображений относительно динамики идентичностей.

Во-первых, степень рефлексивности идентичности, в частности национальной или конфессиональной, определяет не только ее смысловую насыщенность, но и связь с общим социокультурным контекстом (соответственно, национальной культурой и религией), и чем больше таких связей, тем, с одной стороны, устойчивее и идентичность, и социальная система, а с другой - менее они гибки и способны к инкорпорации инородных элементов и трансформациям в целом. Проблема определения баланса между этими крайностями на данный момент остается нерешенной и может сводиться только к вопросу разделения фундаментальных и зависимых связей. Хорошим примером здесь выступает вопрос о соотношении конфессиональной и национальной идентичностей в современном общественном сознании, выраженный в утверждениях «русский - значит, православный», «башкир - значит, мусульманин» и наоборот. Очевидно, что ни башкирская, ни русская культура, их общественное сознание и социальные институты не привязаны к конфессиональным установкам, хотя последние в определенной мере присутствуют в них. Следовательно, такие утверждения не только означают претензию на поглощение национальных идентичностей конфессиональными, но и отсекают светские и иноконфессиональные группы самих наций и соответствующие культурные контексты и установки. 
Во-вторых, структура данной идентичности может иметь (и, как правило, имеет) неоднородное распределение в социокультурном пространстве, в том числе и среди сообщества носителей этой идентичности. Это касается всех ее элементов, включая атрибутику - не говоря уже о базовых символических связях и формах солидарности. Можно предположить, что чем больше общность, тем менее распространен общий набор элементов и компонентов идентичности, а при значительном разрыве между вариантами таких наборов нелинейно нарастает возможность выделения субидентичностей и образования из них идентичностей полноценных. Здесь существенной проблемой выступает сопоставление распространенности структур идентичности и социальной и коммуникативной инфраструктур, обеспечивающих взаимодействие внутри данной общности. Хорошим примером здесь будут выступать некоторые мигрантские сообщества в России: в нормальных условиях они практически полностью теряют свою специфику в поведении и мышлении, оставляя ее в виде отдельных стереотипных образов, и это наблюдается в тем большей степени, чем полнее они инкорпорированы в обычные структуры и отношения российского общества. Специализированные организации, вроде национально-культурных центров, как правило, не выходят за рамки простого воспроизводства отдельных культурных текстов исходных народов и в целом мало имеют отношения к жизни самого сообщества.

В-третьих, из сочетания первых двух соображений вытекает проблема связности: различия в вариантах идентичностей неизбежны и обусловлены структурно-функциональным и территориальным распределением общности, и чем больше масштаб последнего, тем выше эти различия. Следовательно, для того чтобы из этих различий не складывались полноценные идентичности и не множились обусловленные ими институциональные и дискурсивные разрывы, необходимо постоянное социокультурное сопровождение общей идентичности как таковой, а также специальные меры, которые поддерживали бы на некотором достаточном уровне объем взаимно пересекающихся и единых образов, структур и элементов, позволяющих воспринимать носителями иден- тичности друг друга как «своих» и распространять друг на друга формы солидарности. По сути этот вопрос касается формирования и поддержания дееспособными общенациональной интеллигенции и ее организаций, которые и выполняют эту функцию.

B-четвертых, с этим плотно пересекается вопрос инфраструктурной обеспеченности воспроизводства идентичности: именно от эффективности этой системы во многом зависит ее дееспособность, в том числе купирование разрывов и противоречий. Недостаток обеспечения означает, что воспроизводство идентичности сокращает свой объем, насыщенность и теряет внутреннюю связность, что очевидно. Однако и избыток может столь же пагубно сказаться на функционировании социокультурной общности, поскольку в этом случае ее ресурсы - материальные, социальные и культурные - будут слишком стягиваться на вопросы обеспечения, что не только способно оголить исполнение других функций и институтов социальной системы общности, но и слишком привязать их к воспроизводству идентичности, лишая систему гибкости и самостоятельности. Более того, в этом случае возникает опасность отождествления идентичности, как социокультурного массового феномена, с фиксирующей ее структурой, что означает, строго говоря, подмену понятий в исследовательском плане и некорректное определение структуры общественного сознания - в социальном.

Здесь показательна судьба не только конфессиональных (например, судьба православия и православной церкви в пред- и пореволюционный период), но и политико-идеологических (например, судьба коммунизма и КПСС во второй половине XX в.) сообществ. $\mathrm{B}$ то же время сообщества национальные, хотя и обращающиеся к институтам национального государства, с крахом последнего не распадаются, поскольку продолжают воспроизводиться специфически национальные культура, отношения и т. п., фундирующие собой идентичность (хотя в случае некоторых наций например, югославской - можно говорить о схожем процессе).

В-пятых, множественность идентичностей в рамках социокультурной общности например, национальных, этнических, субэт- 
нических и конфессиональных идентичностей внутри российской национальной, а ранее внутри советской, - иначе ставит вопрос о соотношении их между собой и с идентичностью общей. Если в рамках всякой данной идентичности - частной по отношению к системе в целом - проблема решалась через поддержание выделяющихся из нее вариантов, то здесь ситуация имеет иной характер. Не из единой идентичности выделяются вариативные комплексы и стремятся обособиться, а наоборот, разные идентичности так или иначе объединяются в некоторую систему и согласуются с общей. При этом чем выше социокультурные (в том числе качественные - если мы говорим, например, о разных конфессиях или сельской и городской культурах, и количественные - если мы сравниваем, например, уровни обеспеченности и распространенности) различия между исходными идентичностями, тем сложнее решение проблемы их согласования, поскольку базовых вариантов остается три: ассимиляция, ведущая к утрате частной идентичности; сепарация, направленная на разделение главной и частной идентичности, что не может не вести к их противопоставлению; интеграция, при которой установки главной идентичности инкорпорируются в частную, а сама она в возможно большем масштабе привязывается к принципам «большой» общности. Первый и второй варианты, как ни парадоксально, развиваются совместно, если только частная идентичность не оказывается слишком слабой и не подавляется достаточно быстро: ассимилируемая идентичность неизбежно продуцирует свои радикальные варианты, как можно более активно противопоставляющие себя главной. В то же время третий вариант постоянно грозит перейти к первому или второму.

Именно поэтому в качестве критериев оценки используется не только степень их комплементарности, но и конфликтности. Достаточно часто близкие идентичности с общим разделяемым комплексом установок оказываются резко противопоставлены друг другу, и порой можно утверждать, что их конфликт оказывается не менее и даже более жестким, чем между идентичностями, значительно различающимися между собой. Этот парадоксальный феномен можно объяснить тем, что в конфликте участвуют не столько разные общности, - в этом случае действуют институционально-дискурсивные установки внешнего конфликта, - а части одной, в силу чего в конфликте активируются установки внутреннего конфликта, а стороны воспринимают его как нарушение солидарности и взаимное предательство. Такие противоречия наблюдаются между: национальными сообществами - например, русскими и украинцами, башкирами и татарами; между субэтническими сообществами внутри нации - например, русскими и казаками; между конфессиональными сообществами в рамках одной религии например, православными, католиками и протестантами, салафитами и суфиями.

Наконец, можно сделать несколько заключений более общего характера, касающихся уже всей системы оценки идентичности.

Очевидно, что внешние и внутренние аспекты функционирования идентичности взаимосвязаны. Например, недостаточная рефлексивность и распространенность идентичности сопровождается недостаточной инфраструктурной ее обеспеченностью - либо институциональной, либо дискурсивной, и наоборот. С другой стороны, слабая рефлексивность приводит к нарушению внутренней связности идентичности с выделением и сепарированием ее вариантов и элементов разной степени радикальности, а также к снижению степени ее комплементарности другим идентичностям системы и повышению конфликтности. В то же время нельзя однозначно утверждать функциональную взаимосвязь между отмеченными аспектами - подобно тому, как высокая степень комплементарности идентичностей не означает низкую их конфликтность, высокий уровень рефлексивности не будет означать обязательно высокой комплементарности, связности и распространенности. Связано это с тем, что отмеченные показатели имеют внешний, формальный характер, в то время как полем сопоставления и взаимодействия идентичностей выступает их содержательное сравнение.

\section{ПРИМЕЧАНИЕ}

1 Работа подготовлена в рамках исполнения Государственного задания «Этноконфессиональ- 
ный фактор в формировании российской гражданской идентичности в Республике Башкортостан».

\section{СПИСОК ЛИТЕРАТУРЫ}

1. Абалмасова, Н. Е. Модели конструирования территориальной идентичности / Н. Е. Абалмасова, Э. А. Паин // ХIII Международная научная конференция по проблемам развития экономики и общества : в 4 ч. / под. общ. ред. Е. Г. Ясина. - М. : Издательский дом НИУ ВШЭ, 2012. Ч. 2. - С. $439-446$.

2. Андерсон, Б. Воображаемые сообщества. Размышления об истоках и распространении национализма / Б. Андерсон ; пер. с англ. В. Николаева. М. : КАНОН-пресс-Ц : Кучково поле, 2001. - 288 с.

3. Бергер, П. Социальное конструирование реальности: Трактат по социологии знания / П. Бергер, Т. Лукман ; пер. с англ. Е. Д. Руткевич. М. : Медиум, 1995. - 323 с.

4. Бурдье, П. Начала / П. Бурдье ; пер. с фр. Н. А. Шматко. - M. : Socio-Logos, 1994. -288 c.

5. Винограденко, Г. Г. Социализация, интернализация, идентичность: диалектика взаимосвязи / Г. Г. Винограденко, И. В. Фролова // Вестник Башкирского университета. - 2011. - Т. 16, № 4. С. $1389-1391$.

6. Гидденс, Э. Устроение общества: Очерк теории структурации : пер. с англ. / Э. Гидденс. 2-е изд. - М. : Академический Проект, 2005. - 528 с.

7. Гоффман, И. Представление себя другим в повседневной жизни / И. Гоффман ; пер. с англ. А. Д. Ковалева. - М. : Канон-пресс-Ц : Кучково поле, 2000. $-304 \mathrm{c}$.

8. Дюркгейм, Э. О разделении общественного труда. Метод социологии : пер. с фр. / Э. Дюркгейм. - М. : Наука, 1991. - 576 с.

9. Кули, Ч. Х. Человеческая природа и социальный порядок / Ч. Кули ; пер. с англ. А. Б. Толстова. - М. : Идея-Пресс, 2000. - 320 с.

10. Мид, Дж. Разум, Я и общество (главы из книги) / Дж. Мид // Социальные и гуманитарные науки. Отечественная и зарубежная литература. Серия 11, Социология. Реферативный журнал. 1997. - № 4- С. 162-195.

11. Нации и национализм / Б. Андерсон, О. Бауэр, М. Хрох [и др.] ; пер с англ. Л. Е. Переяславцевой, М. С. Панина, М. Б. Гнедовского. - М. : Праксис, 2002. - 416 c.

12. Тишков, В. А. Национальная идентичность и духовно-культурные ценности российского народа / В. А. Тишков. - СПб. : СПбГУП, 2010. - 36 с.

13. Фролова, И. В. Этническая и надэтническая идентичность через призму индивидуального и коллективного: философско-политологический анализ / И. В. Фролова // Сборник материалов Всероссийской научно-практической конференции «Этносы и формирование гражданской нации: диалектика российской национальной политики». Уфа : БАГСУ, 2014. - С. 12-16.

\section{REFERENCES}

1. Abalmasova N.E., Pain E.A. Modeli konstruirovaniya territorialnoy identichnosti [Models of Construction of Territorial Identity]. XIII Mezhdunarodnaya nauchnaya konferentsiya po problemam razvitiya ekonomiki i obshchestva: $v 4 \mathrm{ch}$. [Proceedings of the 13th International Conference on the Issues of Economics and Society Development]. Moscow, NIU VShE Publ., 2012, pp. 439-446.

2. Anderson B. Voobrazhaemye soobshchestva. Razmyshleniya ob istokakh $i$ rasprostranenii natsionalizma [Imagined Communities. Contemplations on the Origins and Spread of Nationalism]. Moscow, KANON-Press, 2001. 288 p.

3. Berger P., Luckmann T. Sotsialnoe konstruirovanie realnosti: Traktat po sotsiologii znaniya [The Social Construction of Reality: A Treatise on the Sociology of Knowledge]. Moscow, Medium Publ., 1995. 323 p.

4. Bourdieu P. Nachala [Origins]. Moscow, Socio-Logos, 1994. 288 p.

5. Vinogradenko G.G., Frolova I.V. Sotsializatsiya, internalizatsiya, identichnost: dialektika vzaimosvyazi [Socialization, Internalization, Identity: Dialectic of Interrelation]. Vestnik Bashkirskogo universiteta, 2011, vol. 16, no. 4, pp. 1389-1391.

6. Giddens A. Ustroenie obshchestva: ocherk teorii strukturatsii [The Constitution of Society. Outline of the Theory of Structuration]. Moscow, Akademicheskiy Proekt Publ., 2005. 528 p.

7. Goffman E. Predstavlenie sebya drugim v povsednevnoy zhizni [The Presentation of Self in Everyday Life]. Moscow, KANON-Press, 2000. 304 p.

8. Durkheim E. O razdelenii obshchestvennogo truda. Metod sotsiologii [The Division of Labour in Society. The Rules of Sociological Method]. Moscow, Nauka Publ., 1991. 576 p.

9. Kuli Ch. Chelovecheskaya priroda $i$ sotsialnyy poryadok [Human Nature and the Social Order]. Moscow, Idea-Press, 2000. 320 p.

10. Mid D. Razum, Ya i obshchestvo (glavy iz knigi) [Mind, Self, and Society (Book Chapters)]. Sotsialnye i gumanitarnye nauki. Otechestvennaya $i$ zarubezhnaya literatura. Seriya 11, Sotsiologiya. Referativnyy zhurnal [Social Sciences and Humanities. Russian and Foreign Literature. Abstract Journal], 1997, no. 11, pp. 162-195. 


\section{ФИЛОСОФИЯ}

11. Anderson B., Bauer O., Khrokh M. Natsii i natsionalizm [Nations and Nationalism]. Moscow, Praxis Publ., 2002. 416 p.

12. Tishkov V.A. Natsionalnaya identichnost $i$ dukhovno-kulturnye tsennosti rossiyskogo naroda [National Identity and Cultural Values of Russians]. Saint Petersburg, SPbGUP Publ., 2010. 36 p.

13. Frolova I.V. Etnicheskaya i nadetnicheskaya identichnost cherez prizmu individualnogoi kollektivnogo: filosofsko-politologicheskiy analiz [Ethnic and SupraEthnic Identity in the Context of the Individual and the Collective: Philosophical and Political Analysis]. Sbornik materialov Vserossiyskoy nauchno-prakticheskoy konferentsii «Etnosy i formirovanie grazhdanskoy natsii: dialektika rossiyskoy natsionalnoy politiki» [Proceedings of the All-Russian Scientific Conference "Ethnos and Civil Nation: Dialectic of Russian National Politics"]. Ufa, BAGSUPubl., 2014,pp. 12-16.

\section{Information about the Authors}

Ilya V. Demichev, Candidate of Philosophical Sciences, Researcher at the Center of Sociocultural Analysis, Institute of Strategic Research of Republic Bashkortostan, Kirova St., 15, 450008 Ufa, Russian Federation, senmerv@mail.ru.

Gulfina D. Sultanova, Junior Researcher at the Center of Sociocultural Analysis, Institute of Strategic Research of Republic Bashkortostan, Kirova St., 15, 450008 Ufa, Russian Federation, gulsultan@mail.ru.

\section{Информация об авторах}

Илья Валерьевич Демичев, кандидат философских наук, научный сотрудник Центра социокультурного анализа, Институт стратегических исследований Республики Башкортостан, ул. Кирова, 15, 450008 г. Уфа, Российская Федерация, senmerv@mail.ru.

Гульфина Дамировна Султанова, младший научный сотрудник Центра социокультурного анализа, Институт стратегических исследований Республики Башкортостан, ул. Кирова, 15, 450008 г. Уфа, Российская Федерация, gulsultan@mail.ru. 